\title{
Right atrial contractile dynamics are impaired in patients with postcapillary pulmonary hypertension
}

\author{
CONSTANZE BENING ${ }^{1,2}$ and RAINER LEYH ${ }^{2}$ \\ ${ }^{1}$ Department of Cardiothoracic and Vascular Surgery, Medical Centre of The Johannes Gutenberg University of Mainz, \\ Mainz 55131; ${ }^{2}$ Department of Cardiothoracic Surgery, University Hospital Würzburg, Würzburg 97080, Germany
}

Received December 27, 2015; Accepted April 6, 2016

DOI: $10.3892 /$ etm.2016.3399

\begin{abstract}
Left ventricular (LV) dysfunction in conjunction with postcapillary pulmonary hypertension $(\mathrm{PH})$ is frequently associated with right ventricular (RV) dysfunction, determining the patient prognosis. Compensatory mechanisms for RV dysfunction have not been previously evaluated in detail. Since calcium dependent right atrial (RA) dynamics are a surrogate for RA contractile properties, the present study examined the calcium dependency of RA tissue obtained from patients with or without postcapillary $\mathrm{PH}$. In total, 15 patients with $\mathrm{PH}$ (PH group; mean age, 70.7 \pm 7.2 years) and 10 patients without postcapillary $\mathrm{PH}$ (non-PH group; mean age, $55.7 \pm 11.8$ years) who were scheduled to undergo elective left heart valve surgery were included in the current study. Calcium concentration ( $\mathrm{pCa}$; shown as the negative $\log _{10}$ ) against force curves were generated, while LV and RV function was evaluated by echocardiography. Echocardiography data revealed a significantly reduced LV function in the PH group, while the RV function was preserved in the two groups, precluding overt $\mathrm{RV}$ dysfunction. In the $\mathrm{PH}$ group, significantly reduced force values were detected at high $\mathrm{pCa}$ values when compared with the non-PH group force, indicating impaired RA function. Furthermore, reduced calcium sensitivity was observed (which was determined as the $\mathrm{pCa}$ at half maximal activation) in the PH group, and the presence of a compensatory mechanism for reduced force capacity was hypothesized. In conclusion, the preliminary results of the current study showed impaired RA contractile properties in postcapillary hypertension with preserved RV function. The diminished RA compensatory mechanisms may lead to accelerated RV dysfunction in the clinical course of postcapillary $\mathrm{PH}$.
\end{abstract}

Correspondence to: Dr Constanze Bening and Professor Rainer Leyh, Department of Cardiothoracic Surgery, University Hospital Würzburg, 6 Oberdürrbacher Street, Würzburg 97080, Germany

E-mail: constanze.bening@googlemail.com

E-mail: leyh_r@ukw.de

Key words: postcapillary pulmonary artery hypertension, skinned fibers, calcium sensitivity

\section{Introduction}

Pulmonary hypertension (PH) is a pathophysiological disorder that may involve multiple clinical conditions and can complicate numerous cardiovascular and respiratory diseases (1). The incidence of $\mathrm{PH}$ is 97 cases per million with a female-to-male ratio of 1.8 in the UK (1). Left-sided heart failure is considered to be the most common cause of PH. Furthermore, PH may have clinical consequences on the right-side heart function; however, severe PH in these cases is relatively uncommon (1).

Postcapillary $\mathrm{PH}$ in patients with left ventricular (LV) dysfunction is a well-defined risk factor for right ventricular (RV) heart failure and subsequent increased morbidity and mortality $(2,3)$. Compensatory mechanisms to overcome RV dysfunction are not well defined for these patients, and only limited data are available in the literature about dealing with the effect of postcapillary $\mathrm{PH}$ on right atrial (RA) dynamics and contractile features $(4,5)$.

For precapillary $\mathrm{PH}, \mathrm{RA}$ compensatory mechanisms have been described in animal models with inconclusive results $(6,7)$. In general, precapillary PH RV pressure overload leads to myocardial hypertrophy (7), with the detrimental effect of RV diastolic dysfunction $(6,8,9)$. Thus, RA function is the critical factor for RV filling, and any RA dysfunction may initiate right heart failure in patients with $\mathrm{PH}(6,8)$. The compensatory mechanism for RV diastolic dysfunction involves increased RA contractility, thus maintaining the RV filling (6). The importance of RA function is underlined in a study by Shiina et al (10), which described a strong correlation between right heart failure and reduced RA contractility in patients with chronic precapillary $\mathrm{PH}$.

The aim of the present study was to evaluate RA function in postcapillary $\mathrm{PH}$ in patients with LV dysfunction due to left heart valve pathology. Since RA calcium-dependent skinned fiber dynamics are a surrogate for RA contractile properties, the calcium-dependent RA contractile dynamics were investigated in patients scheduled to undergo elective left heart valve surgery who presented with or without postcapillary $\mathrm{PH}$.

\section{Patients and methods}

Ethics. The study was approved by the Ethics Committee of the Medical Association Rheinhessen. All patients provided 
Table I. Data presented as mean \pm standard deviation, or as \% (n) unless otherwise indicated.

\begin{tabular}{|c|c|c|c|}
\hline Variable & PH group $(n=15)$ & Non-PH group $(n=10)$ & P-value \\
\hline Age, years & $70.70 \pm 7.20$ & $55.70 \pm 11.80$ & 0.008 \\
\hline Female, n (\%) & $9(60)$ & $4(6)$ & 0.900 \\
\hline Height, cm & $168.00 \pm 9.60$ & $171.00 \pm 13.00$ & 0.900 \\
\hline Weight, kg & $68.00 \pm 12.00$ & $76.00 \pm 17.00$ & 0.700 \\
\hline Body surface area, $\mathrm{m}^{2}$ & $1.78 \pm 0.90$ & $1.90 \pm 0.70$ & 0.900 \\
\hline Body-mass index & $23.00 \pm 3.80$ & $25.40 \pm 3.80$ & 0.800 \\
\hline COPD, n $(\%)$ & $0(0)$ & $0(0)$ & \\
\hline Diabetes mellitus, n (\%) & $3(20)$ & $0(0)$ & 0.050 \\
\hline Creatinine $(\mathrm{mg} / \mathrm{dl})$ & $1.01 \pm 0.80$ & $0.67 \pm 0.40$ & 0.700 \\
\hline Chronic atrial fibrillation, $\mathrm{n}(\%)$ & $8(53)$ & $2(20)$ & 0.020 \\
\hline PAVD, n $(\%)$ & $1(6.6)$ & $0(0)$ & 0.800 \\
\hline Stroke incident, n (\%) & $0(0)$ & $0(0)$ & \\
\hline Arterial hypertension, n (\%) & $8(53)$ & $5(50)$ & 0.900 \\
\hline NYHA class III-IV, n (\%) & $5(38)$ & $0(0)$ & 0.030 \\
\hline $\mathrm{LVEF}, \%$ & $47.00 \pm 0.14$ & $60.00 \pm 0.50$ & 0.007 \\
\hline
\end{tabular}

PH, pulmonary hypertension; COPD, chronic obstructive pulmonary disease, PAVD, peripheral arterial venous disease; NYHA, New York Heart Association; LVEF, left ventricular ejection fraction.

written informed consent for the use of intraoperative resected tissue in further research examination. The study was performed according to the Declaration of Helsinki (11).

Patients. A retrospective study was performed using prospectively collected data from patients scheduled to undergo elective left heart valve surgery due to aortic and mitral valve disease at the Department of Cardiothoracic and Vascular Surgery of the University of Mainz (Mainz, Germany) between January 2011 and December 2014. In total, 25 patients undergoing cardiac surgery were included in the present study. The patients were divided into two groups, as follows: The postcapillary PH group (PH group), consisting of 15 patients, and the non-postcapillary $\mathrm{PH}$ group (non-PH group), consisting of 10 patients. The patients were classified according to the New York Heart Association (NYHA) classification system (12). Patient demographics and characteristics are presented in Table I.

Inclusion and exclusion criteria. Postcapillary PH was defined by a mean pulmonary artery pressure (mPAP) of $\geq 25 \mathrm{mmHg}$ (iE33 xMATRIX Echocardiography System; Philips Healthcare, Amsterdam, The Netherlands) in the presence of left-sided valvular heart disease and the absence of any primary pulmonary artery hypertension (PAH), according to previously reported guidelines (13). Preserved RV function was defined when the tricuspid annular plane systolic excursion (TAPSE) was $\geq 16 \mathrm{~mm}$ (14).

Patients with precapillary arterial hypertension, idiopathic, heritable forms of PAH, PAH associated with infectious disease, connective tissue diseases, congenital diseases, pulmonary veno-occlusive diseases, other pulmonary diseases and chronic thromboembolic $\mathrm{PH}$ were excluded from the current study. Furthermore, patients presenting as emergency cases, patients requiring cardiac procedures with the exception of aortic and mitral valve surgery, endocarditis cases, and patients with clinical and echocardiographic signs of chronic, acute right or acute left heart failure were also excluded.

Clinical setting. Hemodynamic data from all patients were obtained preoperatively by means of standard right heart catheterization, as described previously (1). The mean RA pressure (mRAP), mPAP and pulmonary artery wedge pressure (PAWP) were recorded (iE33 xMATRIX echocardiography system).

Preoperative echocardiography was performed in all patients (iE33 xMATRIX echocardiography system). Standard echocardiographic measurements were performed in expiration. The following parameters were measured: The LV ejection fraction (LVEF) was determined according to the biplane Simpson's method (14). In addition, dilatation of the right and left atria and ventricles was assessed by transthoracic echocardiography (2D and M-mode; iE33 xMATRIX echocardiography system). LV dilatation was defined when the LV end-diastolic diameter (LVEDD) was $>55 \mathrm{~mm}$ and RV dilation was determined when the RV end-diastolic diameter was $>30 \mathrm{~mm}$. Similarly, RA dilatation was defined when the minor RA axis was $>4.4 \mathrm{~cm}$ and the major axis was $>5.3 \mathrm{~cm}$, whereas left atrial dilatation was defined when the end-systolic diameter was $>40 \mathrm{~mm}$ (M-mode).

TAPSE was measured with two-dimensional M-mode echocardiography. However, the RV diastolic function in presence of tricuspid regurgitation (TR) and atrial fibrillation was not assessed. Echocardiographic views, measurements, as well as calculations, were performed according to recent guidelines $(14,15)$.

Skinned fiber preparation. Skinned fiber preparation was performed as previously described $(16,17)$. Briefly, the fibers 


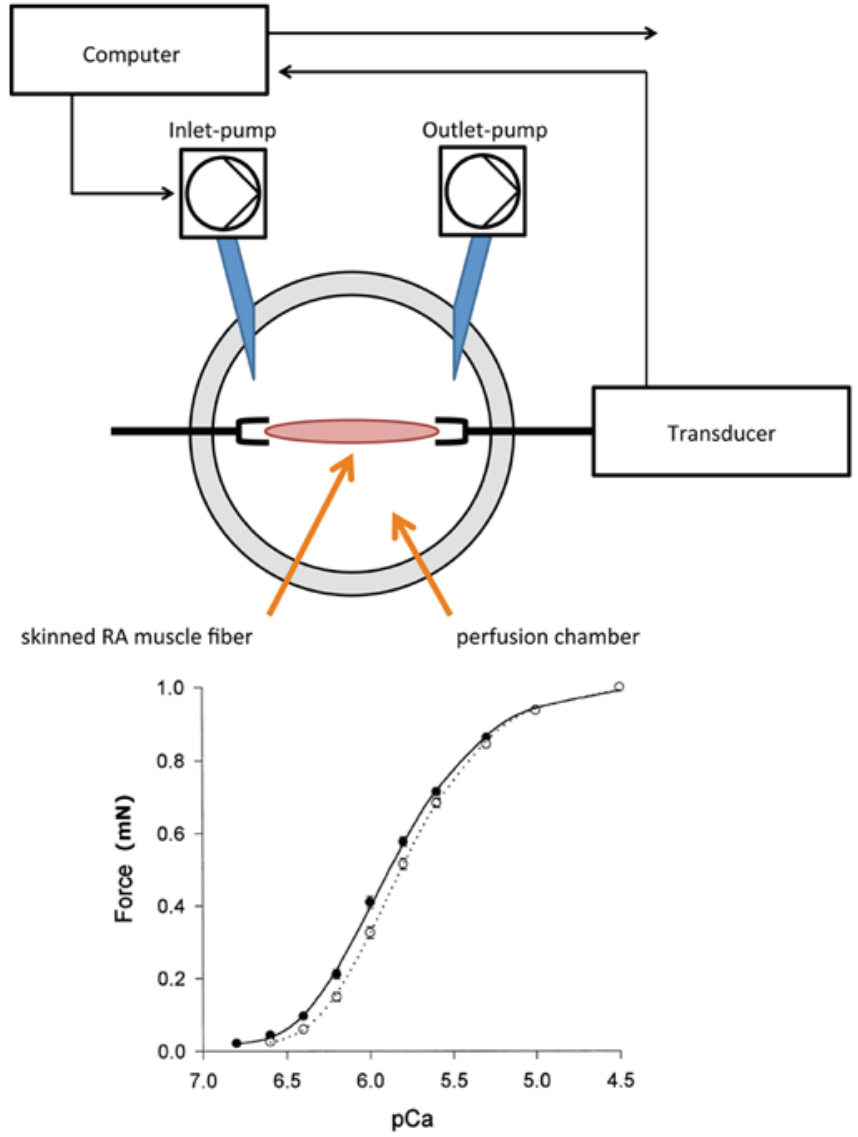

Figure 1. Experimental set-up of the 'muscle investigation system' used in the present study. The master pump transports a specific amount of calcium solution into the perfusion chamber, and the slave pump withdraws the same amount out of the perfusion chamber. Thus, the calcium concentration increases in the perfusion chamber and the pCa-force curve is recorded by the attached computer system. $\mathrm{pCa}$, calcium concentration (given as the negative $\log _{10}$ ).

were collected during surgery following resection of the right auricle. Using a non-touch-technique, the auricle was transferred in an ice-cooled vial $\left(4^{\circ} \mathrm{C}\right)$ containing a modified cardioplegic solution (Krebs-Henseleit solution, which included: $118.07 \mathrm{mmol} / \mathrm{l} \mathrm{NaCl}, 11.1 \mathrm{mmol} / 1 \mathrm{C}_{6} \mathrm{H}_{12} \mathrm{O}_{6} \cdot \mathrm{H}_{2} \mathrm{O}$, $4.7 \mathrm{mmol} / \mathrm{l} \mathrm{KCl}, 25 \mathrm{mmol} / \mathrm{l} \mathrm{NaHCO}, 1.2 \mathrm{mmol} / 1 \mathrm{KH}_{2} \mathrm{PO}_{4}$, $\left.1.2 \mathrm{mmol} / 1 \mathrm{MgSO}_{4} .7 \mathrm{H}_{2} \mathrm{O}, 1.8 \mathrm{mmol} / 1 \mathrm{CaCl}_{2} \cdot 2 \mathrm{H}_{2} \mathrm{O}\right)$ and $30 \mathrm{mmol} / 1$ 2,3-butanedione monoxime $\left(\mathrm{C}_{4} \mathrm{H}_{7} \mathrm{NO}_{2}\right)$ as an ATP-sensitive potassium channel inhibitor. For examination, the tissue was transferred to a dish containing an ice-cooled $\left(4^{\circ} \mathrm{C}\right)$ preparation solution, with the following contents: $68.08 \mathrm{mM} \mathrm{C}_{3} \mathrm{H}_{4} \mathrm{~N}_{2}, 65.01 \mathrm{mM} \mathrm{NaN}_{3}, 380.4 \mathrm{mM}$ $\mathrm{C}_{14} \mathrm{H}_{24} \mathrm{~N}_{2} \mathrm{O}_{10}, 154.3 \mathrm{mM} \mathrm{C}_{4} \mathrm{H}_{10} \mathrm{O}_{2} \mathrm{~S}_{2}, 203.3 \mathrm{mM} \mathrm{MgCl} \cdot 6 \mathrm{H}_{2} \mathrm{O}$, and $605.2 \mathrm{mM} \mathrm{C}_{10} \mathrm{H}_{14} \mathrm{~N}_{5} \mathrm{O}_{13} \mathrm{P}_{3} \mathrm{Na}_{2}$. The muscle bundles were then resected out of the auricle and transferred to a test tube containing the modified preparation solution with $1 \%$ Triton X-100 in order to permeabilize the membrane of the fibers, with incubation for $24 \mathrm{~h}$ at $4^{\circ} \mathrm{C}$ on a shaking device. The purpose of these preparatory steps was to remove all membrane-dependent properties (also known as 'skinning'). Following this skinning process, the RA muscle bundles were transferred to a separate ice-cooled $\left(4^{\circ} \mathrm{C}\right)$ dish containing preparation solution, in order to prepare single muscle stripes (size, 2-2,5x0,3 mm) under the microscope (magnification, $\mathrm{x} 10$;
Leica DM1000; Leica Microsystems GmbH, Wetzlar, Germany).

Log10 calcium concentration ( $p C a$ ) against force measurements in RA tissue. A muscle investigation system (Gradient Program; Scientific Instruments, Heidelberg, Germany) was used to expose the RA fibers to gradual increase of $\mathrm{pCa}$ for force measurements. The experimental set-up is depicted in Fig. 1. The RA fibers were fixed in the perfusion chamber and incubated with a relaxation solution, containing the following: $68.08 \mathrm{mM} \mathrm{C}_{3} \mathrm{H}_{4} \mathrm{~N}_{2}, 327.2 \mathrm{mM} \mathrm{C}_{4} \mathrm{H}_{8} \mathrm{~N}_{3} \mathrm{O}_{5} \mathrm{PNa}_{2} .4 \mathrm{H}_{2} \mathrm{O}$, $65.01 \mathrm{mM} \mathrm{NaN}_{3}, 380.4 \mathrm{mM} \mathrm{C}_{14} \mathrm{H}_{24} \mathrm{~N}_{2} \mathrm{O}_{10}, 203.3 \mathrm{mM} \mathrm{MgCl}_{2}$, $154.2 \mathrm{mM} \mathrm{C}_{4} \mathrm{H}_{10} \mathrm{O}_{2} \mathrm{~S}_{2}, 605.2 \mathrm{mM} \mathrm{C}_{10} \mathrm{H}_{14} \mathrm{~N}_{5} \mathrm{O}_{13} \mathrm{P}_{3} \mathrm{Na}_{2}$, and $400 \mathrm{U} / \mathrm{ml}$ creatine kinase. By adding $147.02 \mathrm{mM} \mathrm{CaCl}_{2}$ to the relaxation solution, a pCa-force curve was created. $\mathrm{pCa}$ was shown as the negative $\log _{10}$ of the calcium concentration. A specifically designed software (Gradient Program; Scientific Instruments) was used to calculate the amount of calcium required to achieve a stepwise increase in $\mathrm{pCa}$ according to the equation described by Morano et al (16) and Fabiato and Fabiato (17). The pCa included concentrations between 6.5 and 4.0 , in 0.5 increments. For each patient, a set of three RA fibers underwent calcium-induced force measurements. Thus, a total of 45 samples were evaluated in the PH group and 30 samples in the non-PH group.

Statistical analysis. Statistical analysis was performed using SPSS software (version 23; IBM Corp., Armonk, NY, USA). Patient continuous demographics are presented as the mean \pm standard deviation, while categorical data are presented as percentages. Normal distribution was tested with Shapiro-Wilk test. Continuous variables were statistically analyzed with Welch's t-test, and categorical data were compared with Wilcoxon signed-rank test and $\chi^{2}$ test. Two-sided P-values of $<0.05$ were considered to indicate statistically significant differences.

\section{Results}

Demographics. The demographic information and clinical data of the patients are depicted in Table I. When compared with the non-PH group, patients in the $\mathrm{PH}$ group had a significantly higher age $(\mathrm{P}=0.008)$ and higher prevalence of atrial fibrillation $(\mathrm{P}=0.02)$. In addition, a higher proportion of $\mathrm{PH}$ patients presented class III-IV disease (according to the NYHA classification; $\mathrm{P}=0.03)$ and a reduced $\operatorname{LVEF}(\mathrm{P}=0.007)$.

Indication for left heart surgery differed between the two groups, with mitral valve regurgitation surgery required in significantly more $\mathrm{PH}$ group patients, as the compared with the non-PH group (100\% vs. $30 \%$, respectively; P 0.001$)$.

Echocardiography. The hemodynamic and echocardiographic data of the patients are shown in Table II. In the PH group, mean PAWP, mPAP and mRAP were significantly higher, as compared with the values in the non-PH group (all $\mathrm{P}<0.001$; Figs. 2-4), whereas the LVEF was significantly reduced $(\mathrm{P}=0.007$; Table II $)$ as an expression of post capillary $\mathrm{PH}$ with impaired LV function. Although LV dilatation was more frequently observed in the $\mathrm{PH}$ group ( $\mathrm{P}=0.03$; Table II), the LVEDD revealed no differences between the two groups 
Table II. Patient hemodynamic parameters.

\begin{tabular}{lccc}
\hline Variable & PH group $(\mathrm{n}=15)$ & Non-PH group $(\mathrm{n}=10)$ & P-value \\
\hline LV ejection fraction, $\%$ & $47.00 \pm 0.14$ & $60.00 \pm 0.05$ & 0.007 \\
Mean LVEDD, mm & $60.00 \pm 11.00$ & $48.00 \pm 14.00$ & 0.800 \\
TAPSE, mm & $18.00 \pm 4.40$ & $21.50 \pm 2.20$ & 0.800 \\
Tricuspid regurgitation $\geq \mathrm{II}^{\circ}, \mathrm{n}(\%)$ & $10(67)$ & $0(0)$ & 0.030 \\
Mitral valve regurgitation, $\mathrm{n}(\%)$ & $15(100)$ & $3(50)$ & 0.030 \\
Mitral valve regurgitation $\geq \mathrm{II}^{\circ}, \mathrm{n}(\%)$ & $15(100)$ & $3(30)$ & 0.001 \\
Aortic valve stenosis, $\mathrm{n}(\%)$ & $6(40)$ & $2(20)$ & 0.700 \\
Aortic regurgitation, $\mathrm{n}(\%)$ & $0(0)$ & $4 \pm 2.4$ & 0.050 \\
mRAP, mmHg & $10.00 \pm 2.70$ & $21.30 \pm 1.30$ & $<0.001$ \\
mPAP, mmHg & $52.6 \pm 17$ & $8.26 \pm 3.00$ & $<0.001$ \\
Mean PAWP, mmHg & $23.00 \pm 1.00$ & $2(20)$ & $<0.001$ \\
RA dilatation, $\mathrm{n}(\%)$ & $12(80)$ & $1(10)$ & 0.001 \\
RV dilatation, $\mathrm{n}(\%)$ & $3(20)$ & $2(20)$ & 0.020 \\
LA dilatation, $\mathrm{n}(\%)$ & $11(73)$ & $1(10)$ & 0.040 \\
LV dilatation, $\mathrm{n}(\%)$ & $7(47)$ & 0.030 \\
\hline
\end{tabular}

Data are presented as the mean \pm standard deviation or as $\mathrm{n}(\%)$, unless otherwise indicated. $\mathrm{PH}$, pulmonary hypertension; LV, left ventricular; LVEDD, left ventricular end-diastolic diameter; TAPSE, tricuspid annular plane systolic excursion; mRAP, mean right atrial pressure; mPAP, mean pulmonary artery pressure; PAWP, pulmonary artery wedge pressure; RA, right atrial; RV, right ventricular; LA, left atrial.

Table III. pCa force values (mean \pm standard deviation).

\begin{tabular}{lccc}
\hline Variable & $\begin{array}{c}\text { PH group } \\
(\mathrm{n}=15)\end{array}$ & $\begin{array}{c}\text { Non-PH group } \\
(\mathrm{n}=10)\end{array}$ & P-value \\
\hline $\mathrm{pCa}, \mathrm{mN}$ & & & \\
4.0 & $2.90 \pm 0.30$ & $4.1 \pm 0.50$ & 0.001 \\
4.5 & $2.20 \pm 0.30$ & $2.9 \pm 0.20$ & 0.010 \\
5.0 & $1.70 \pm 0.20$ & $2.2 \pm 0.30$ & 0.010 \\
5.5 & $1.40 \pm 0.04$ & $1.2 \pm 0.03$ & 0.800 \\
6.0 & $1.00 \pm 0.04$ & $0.8 \pm 0.03$ & 0.900 \\
6.5 & $0.60 \pm 0.05$ & $0.4 \pm 0.03$ & 0.800 \\
$\mathrm{pCa}^{2+}{ }_{50}$ & 5.5 & 5.0 & 0.010
\end{tabular}

$\mathrm{PH}$, pulmonary hypertension; $\mathrm{pCa}^{2+}{ }_{50}$, calcium concentration at which half maximal activation was achieved; $\mathrm{pCa}$, calcium concentration (given as the negative $\log _{10}$ ).

$(60 \pm 11 \mathrm{~mm}$ in the $\mathrm{PH}$ group vs. $48 \pm 14 \mathrm{~mm}$ in the non-PH group; $\mathrm{P}=0.8$; Table II). Similarly, TAPSE did not differ significantly between the two groups $(18 \pm 4.4 \mathrm{~mm}$ in the $\mathrm{PH}$ group vs. $21.5 \pm 2.2 \mathrm{~mm}$ in the non-PH group; $\mathrm{P}=0.8$; Fig. 5), although the presence of RA dilation ( 80 vs. 20\%; P 0.001 ) and RV dilatation (20 vs. $10 \%$; P 0.02 ) was significantly increased in the PH group compared with the non-PH group (Table II). Furthermore, significantly more patients in the PH group had a $\mathrm{TR} \geq \mathrm{II}^{\circ}$, while $\mathrm{TR}$ was more frequently observed in the $\mathrm{PH}$ group (86 vs. $40 \%$; $\mathrm{P}=0.04$ ), when compared with the non-PH group.

pCa-force measurements. The pCa-force values of the two groups are demonstrated in Table III. Higher force values

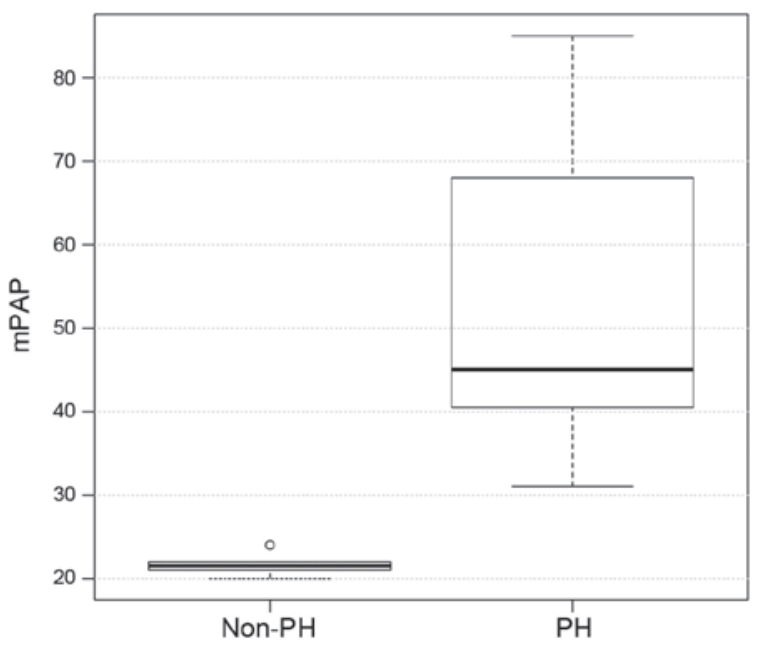

Figure 2. Distribution of the mPAP values in the $\mathrm{PH}$ and non-PH groups. $\mathrm{PH}$, pulmonary hypertension; mPAP, mean pulmonary artery pressure.

were observed at the three highest concentrations of calcium, with force values in the non-PH group being significantly increased when compared with the $\mathrm{PH}$ group (at pCa 4.0: $4.1 \pm 0.5$ vs. $2.9 \pm 0.3 \mathrm{mN}, \mathrm{P}=0.001$; at $\mathrm{pCa} 4.5: 2.9 \pm 0.2$ vs $2.2 \pm 0.3 \mathrm{mN}, \mathrm{P}=0.01$; at $\mathrm{pCa} 5.0: 2.2 \pm 0.3$ vs. $1.7 \pm 0.2 \mathrm{mN}$, $\mathrm{P}=0.01)$. In addition, calcium sensitivity, which was defined as the $\mathrm{pCa}$ at half maximal force (shown as $\mathrm{pCa}^{2+}{ }_{50}$ ) was different among groups. The $\mathrm{PH}$ group achieved half maximal force at a $\mathrm{pCa}$ of 5.5, whereas the non-PH group reached half maximal force at a $\mathrm{pCa}$ of 5.0. These findings suggest that patients with $\mathrm{PH}$ develop half maximal force at a lower concentration of calcium, when compared with non-PH patients; therefore, the affinity to calcium is higher in the $\mathrm{PH}$ group. 


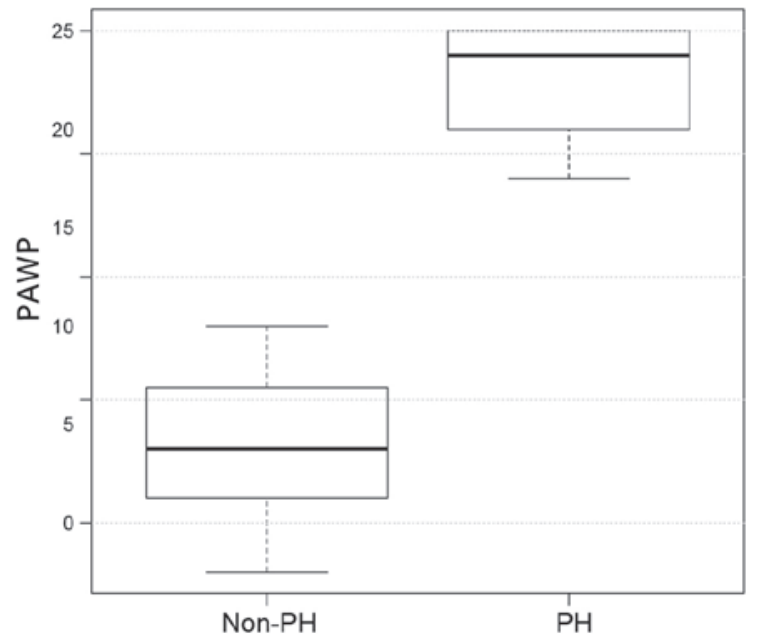

Figure 3. Distribution of the PAWP values in the PH and non-PH groups. PH, pulmonary hypertension; PAWP, pulmonary artery wedge pressure.

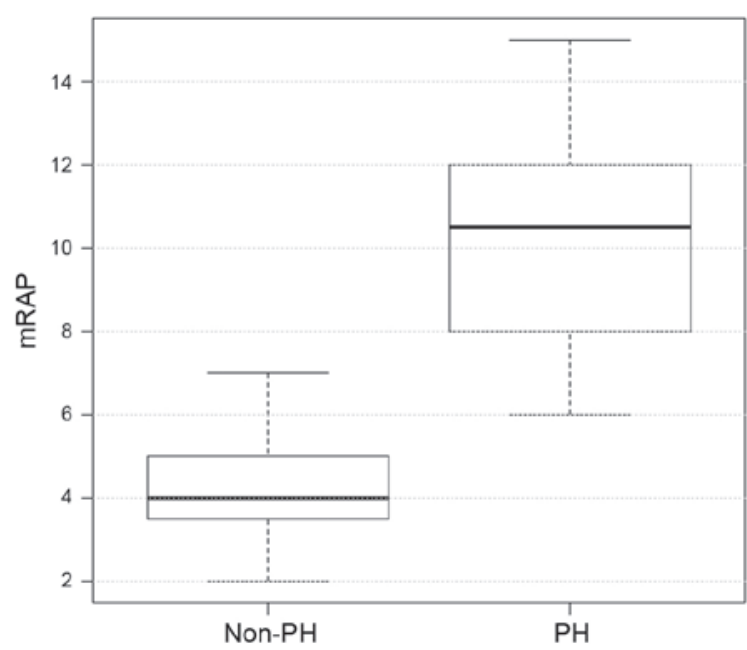

Figure 4. Distribution of the mRAP values in the PH and non-PH groups. PH, pulmonary hypertension; mRAP, mean right atrial pressure.

\section{Discussion}

The present study investigated an RA skinned fiber model in patients with postcapillary PH due to valvular LV dysfunction, and the results showed significantly reduced contractile forces when compared with those in patients without $\mathrm{PH}$. These data may be interpreted as signs of impaired RA compensatory mechanism in postcapillary PH. Notably, patients in the PH group had absence of clinical and echocardiographic signs of overt RV impairment, as indicated by the TAPSE values. According to previous studies (18-20), TAPSE is a reliable echocardiographic parameter for the assessment of RV function in the presence of postcapillary PH. TAPSE has been recently reported to be equal or even superior to other RV-echo-Doppler indices $(18,19)$. Guazzi et al $(21)$ showed that TAPSE and systolic PAP reflect the contractile state of the RV in clinical settings; in this echocardiographic study about RV contractile function, TAPSE and systolic PAP used as in vivo indices for RV length and developed force were found to better reflect the contractile state of RV. However, it was not possible

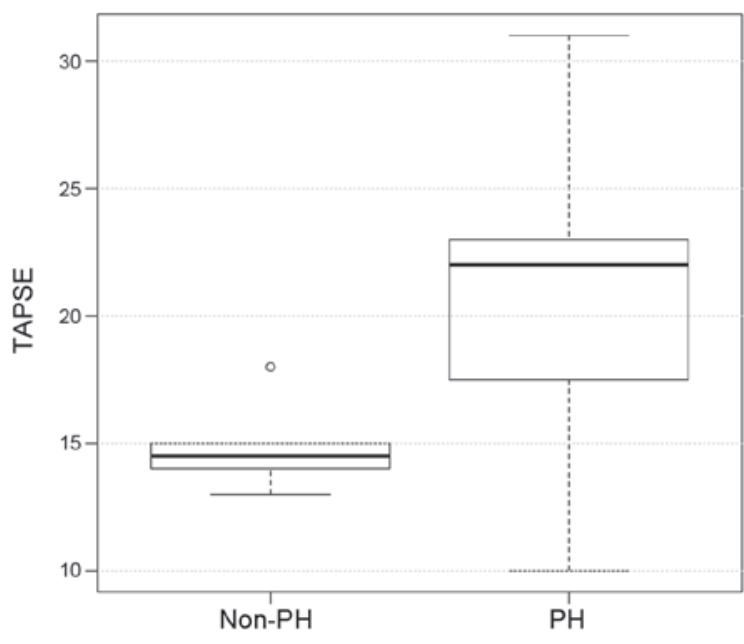

Figure 5. Distribution of the TAPSE values in the $\mathrm{PH}$ and non-PH groups. $\mathrm{PH}$, pulmonary hypertension; TAPSE, tricuspid annular plane systolic excursion.

to exclude latent RV dysfunction with the methods used in the present study, since TAPSE was at the lower limit of the established values, RA and RV dilatation was present, and a higher incidence of TR was detected. Furthermore, diastolic dysfunction was not evaluated in the present study population due to the high incidence of atrial fibrillation and TR, factors that make determination of RV diastolic impairment difficult. Thus, based on the observations, RV dysfunction can be suspected.

In precapillary $\mathrm{PH}$, impaired RA contractility is associated with signs of right heart failure (10). Since no clinical signs of right heart failure were observed in the present study, but signs of chronic LV dysfunction were detected, it was hypothesized that the patients had chronic LV dysfunction involving the right ventricle at the level of the contractile apparatus albeit with the RV function clinically preserved. Due to the interventricular interaction between LV and RV function, the RV function can be impaired in patients with LV dysfunction. This physiological interaction has to be considered, since up to one third of right-sided stroke occurrence is due to LV septal contraction (22). This interaction has been proven in the clinical setting of chronic volume overload in mitral valve regurgitation. For instance, Le Tourneau et al (23) showed that, in patients with impaired LV systolic function, the RV function is mainly dependent upon LV remodeling and septal function, but only weakly dependent on pulmonary systolic pressure. In precapillary $\mathrm{PH}$, a compensatory mechanism for RV functional impairment involves increased RA contractility, which maintains RV filling over a long period of time $(6,9)$. Considering the importance of interventricular interaction and RA function for RV performance, dysfunction of both components may be detrimental in PH patients. Reduced absolute force values in combination with increased calcium sensitivity in the $\mathrm{PH}$ group indicate that RA compensatory mechanisms are limited in postcapillary PH due to chronic LV dysfunction, which may lead to an accelerated development of RV failure. Only limited clinical data are available on the RA compensatory mechanism for RV-functional adaptation in precapillary and postcapillary $\mathrm{PH}(5,22,24)$. 
The results of animal studies investigating the effect of precapillary hypertension on the RA compensatory mechanism are inconsistent $(9,25)$. For instance, Gaynor et al (6) demonstrated the increase of RA contractility and distensibility as a result of increased RV strain; however, methodological limitations exist, since these data were calculated and not measured. By contrast, studies in rodent models demonstrated that induced $\mathrm{PH}$ resulted in marked reduction of $\mathrm{Ca}^{2+}$-activated force and in reduced maximal $\mathrm{Ca}^{2+}$-dependent force values $(9,25)$. To the best of our knowledge, no animal studies showing the effect of postcapillary hypertension on the RA compensatory mechanism are available. Due to the inconsistent results from animal studies, it can only be speculated whether these data are applicable for the clinical setting of chronic precapillary or postcapillary $\mathrm{PH}$. The majority of clinical studies investigated patients subsequent to heart lung transplantation for severe precapillary $\mathrm{PH}$, and did not focus on cellular RA compensatory mechanisms $(2,5)$. Rain et al $(5,26)$ demonstrated increased stiffness of cardiomyocytes and cardiomyocyte sarcomeres as a result of RV diastolic dysfunction, and increased calcium sensitivity as a compensatory mechanism in RV-myocardial specimens in patients with precapillary $\mathrm{PH}$ and impaired $\mathrm{RV}$ function. Upon investigation of the left ventricle, it was demonstrated that reduced force capacity can be compensated with increased affinity to calcium (27). This compensatory mechanism cannot utilize full force capacity, since increased calcium sensitivity leads to incomplete actin-myosin detachment; therefore, this mechanism compensates only in part for RV myocardial dysfunction (26).

To the best of our knowledge, this is the first study in humans to examine RA tissue exposed to chronic volume overload. However, the present study presented various limitations. Firstly, the number of patients examined in current study was limited. To overcome this drawback, a larger sample size is required to support the current results. In addition, RA tissue was examined, which may not be representative for RV contractile dynamics. However, Vannier et al (28) demonstrated that the myofibrils contractile force of atrial and ventricular fibers show the same contractile and properties, which may support the assumption that these results are representative for the right heart. Another limitation of the present study is that the groups differed concerning the indication for surgery. In the $\mathrm{PH}$ group, mitral valve regurgitation with chronic volume overload and eccentric hypertrophy was the main indication for surgery, whereas in the non-PH group, aortic stenosis with pressure overload and concentric hypertrophy was the predominant indication for surgery. Myocardial hypertrophy is a strong factor influencing maximal calcium activated force and calcium sensitivity in left heart failure in rodents (29), although it remains unclear whether this is also the case in humans. Differences in the manifestation of hypertrophy may have an impact on RA calcium activation, thus influencing the results of the present study. We hypothesize that, although RV systolic function was preserved (TAPSE, $>16 \mathrm{~mm}$ ), the higher prevalence of TR may be a sign of a latent RV impairment that is not yet clinically apparent. This hypothesis requires further investigation with magnet resonance imaging (30).

In conclusion, the present preliminary results in patients with postcapillary PH demonstrated reduced RA contractile forces and increased calcium sensitivity. The present clinical study is the first to show evidence that the RA compensatory mechanism is already impaired at a point in time when no clinical and overt echocardiographic signs of RV dysfunction are present in postcapillary PH. This may have a clinical impact on the timing of surgical intervention, since occurrence of RV dysfunction in left heart disease is a powerful predictor of cardiovascular and overall survival $(23,31)$. The current results may support the policy of early surgical or interventional treatment in patients presenting with left heart valvular pathology. Nevertheless, it has to be considered that these results are only preliminary, and further clinical studies with larger patient cohorts are mandatory to determine the clinical importance of these findings.

\section{Acknowledgements}

The authors would like to thank Mr. Alexander Graf at the Department of Cardiothoracic and Vascular Surgery of the University of Mainz for statistical support.

\section{References}

1. Galiè N, Humbert M, Vachiery JL, Gibbs S, Lang I, Torbicki A, Simonneau G, Peacock A, Vonk Noordegraaf A, Beghetti M, et al: 2015 ESC/ERS Guidelines for the diagnosis and treatment of pulmonary hypertension: The Joint Task Force for the Diagnosis and Treatment of Pulmonary Hypertension of the European Society of Cardiology (ESC) and the European Respiratory Society (ERS): Endorsed by: Association for European Paediatric and Congenital Cardiology (AEPC), International Society for Heart and Lung Transplantation (ISHLT). Eur Respir J 46: 903-975, 2015.

2. Trammell AW, Pugh ME, Newman JH, Hemnes AR and Robbins IM: Use of pulmonary arterial hypertension-approved therapy in the treatment of non-group 1 pulmonary hypertension at US referral centers. Pulm Circ 5: 356-363, 2015.

3. Moraes DL, Colucci WS and Givertz MM: Secondary pulmonary hypertension in chronic heart failure: The role of the endothelium in pathophysiology and management. Circulation 102: 1718-1723, 2000.

4. Murch SD, La Gerche A, Roberts TJ, Prior DL, MacIsaac AI and Burns AT: Abnormal right ventricular relaxation in pulmonary hypertension. Pulm Circ 5: 370-375, 2015.

5. Rain S, Handoko ML, Trip P, Gan CT, Westerhof N, Stienen GJ, Paulus WJ, Ottenheijm CA, Marcus JT, Dorfmüller P, et al: Right ventricular diastolic impairment in patients with pulmonary arterial hypertension. Circulation 128: 2016-2025, 2013.

6. Gaynor SL, Maniar HS, Prasad SM, Steendijk P and Moon MR: Reservoir and conduit function of right atrium: Impact on right ventricular filling and cardiac output. Am J Physiol Heart Circ Physiol 288: H2140-H2145, 2005.

7. Gaynor SL, Maniar HS, Bloch JB, Steendijk P and Moon MR: Right atrial and ventricular adaptation to chronic right ventricular pressure overload. Circulation 112 (Suppl 9): S1212-S1218, 2005.

8. Leeuwenburgh BP, Helbing WA, Steendijk P, Schoof PH and Baan J: Biventricular systolic function in young lambs subject to chronic systemic right ventricular pressure overload. Am J Physiol Heart Circ Physiol 281: H2697-H2704, 2001.

9. Fan D, Wannenburg T and de Tombe PP: Decreased myocyte tension development and calcium responsiveness in rat right ventricular pressure overload. Circulation 95: 2312-2317, 1997.

10. Shiina Y, Funabashi N, Lee K, Daimon M, Sekine T, Kawakubo M, Takahashi M, Yajima R, Tanabe N, Kuriyama T and Komuro I: Right atrium contractility and right ventricular diastolic function assessed by pulsed tissue Doppler imaging can predict brain natriuretic peptide in adults with acquired pulmonary hypertension. Int J Cardiol 135: 53-59, 2009.

11. World Medical Association: World Medical Association Declaration of Helsinki: Ethical Principles for Medial Research Involving Human Subjects. JAMA 284: 3043-3045, 2000.

12. Kossman CE; The Criteria of the New York Heart Association: Diseases of the Heart and Blood Vessels: Nomenclature and Criteria for Diagnosis. 6th edition. Little, Brown and Co., Boston, pp110-114, 1964 
13. Simonneau G, Gatzoulis MA, Adatia I, Celermajer D, Denton C, Ghofrani A, Gomez Sanchez MA, Krishna Kumar R, Landzberg M, Machado RF, et al: Updated clinical classification of pulmonary hypertension. J Am Coll Cardiol 62 (Suppl 25): D34-D41, 2013.

14. Rudski LG, Lai WW, Afilalo J, Hua L, Handschumacher MD, Chandrasekaran K, Solomon SD, Louie EK and Schiller NB: Guidelines for the echocardiographic assessment of the right heart in adults: A report from the American Society of Echocardiography endorsed by the European Association of Echocardiography, a registered branch of the European Society of Cardiology and the Canadian Society of Echocardiography. J Am Soc Echocardiogr 23: 685-713; quiz 786-788, 2010.

15. Lang RM, Bierig M, Devereux RB, Flachskampf FA, Foster E, Pellikka PA, Picard MH, Roman MJ, Seward J, Shanewise JS, et al: Recommendations for chamber quantification: A report from the American Society of Echocardiography's Guidelines and Standards Committee and the Chamber Quantification Writing Group, developed in conjunction with the European Association of Echocardiography, a branch of the European Society of Cardiology. J Am Soc Echocardiogr 18: 1440-1463, 2005.

16. Morano I, Arndt H, Gärtner C and Rüegg JC: Skinned fibers of human atrium and ventricle: Myosin isoenzymes and contractility. Circ Res 62: 632-639, 1988.

17. Fabiato A and Fabiato F: Excitation-contraction coupling of isolated cardiac fibers with disrupted or closed sarcolemmas. Calcium-dependent cyclic and tonic contractions. Circ Res 31: 293-307, 1972

18. Zakaria D, Sachdeva R, Gossett JM, Tang X and O'Connor MJ: Tricuspid annular plane systolic excursion is reduced in infants with pulmonary hypertension. Echocardiography 32: 834-838, 2015.

19. Bano M, Kanaan UB, Ehrlich AC, McCracken C, Morrow G, Oster ME and Sachdeva R: Improvement in tricuspid annular plane systolic excursion with pulmonary hypertension therapy in pediatric patients. Echocardiography 32: 1228-1232, 2015.

20. Damy T, Kallvikbacka-Bennett A, Goode K, Khaleva O, Lewinter C, Hobkirk J, Nikitin NP, Dubois-Randé JL, Hittinger L, Clark AL and Cleland JG: Prevalence of, associations with, and prognostic value of tricuspid annular plane systolic excursion (TAPSE) among out-patients referred for the evaluation of heart failure. J Card Fail 18: 216-225, 2012

21. Guazzi M, Bandera F, Pelissero G, Castelvecchio S, Menicanti L, Ghio S, Temporelli PL and Arena R: Tricuspid annular plane systolic excursion and pulmonary arterial systolic pressure relationship in heart failure: An index of right ventricular contractile function and prognosis. Am J Physiol Heart Circ Physiol 305: H1373-H1381, 2013.
22. Marcus JT, Vonk Noordegraaf A, Roeleveld RJ, Postmus PE, Heethaar RM, Van Rossum AC and Boonstra A: Impaired left ventricular filling due to right ventricular pressure overload in primary pulmonary hypertension: Noninvasive monitoring using MRI. Chest 119: 1761-1765, 2001.

23. Le Tourneau T, Deswarte G, Lamblin N, Foucher-Hossin C, Fayad G, Richardson M, Polge AS, Vannesson C, Topilsky Y, Juthier F, et al: Right ventricular systolic function in organic mitral regurgitation: Impact of biventricular impairment. Circulation 127: 1597-1608, 2013.

24. Ferrari R, Böhm M, Cleland JG, Paulus WJ, Pieske B, Rapezzi C and Tavazzi L: Heart failure with preserved ejection fraction: Uncertainties and dilemmas. Eur J Heart Fail 17: 665-671, 2015.

25. Pérez NG, Hashimoto K, McCune S, Altschuld RA and Marbán E: Origin of contractile dysfunction in heart failure: Calcium cycling versus myofilaments. Circulation 99: 1077-1083, 1999.

26. Rain S, Bos Dda S, Handoko ML, Westerhof N, Stienen G, Ottenheijm C, Goebel M, Dorfmüller P, Guignabert C, Humbert M, et al: Protein changes contributing to right ventricular cardiomyocyte diastolic dysfunction in pulmonary arterial hypertension. J Am Heart Assoc 3: e000716, 2014.

27. Wankerl M, Böhm M, Morani I, Rüegg JC, Eichhorn M and Erdmann E: Calcium sensitivity and myosin light chain pattern of atrial and ventricular skinned cardiac fibers from patients with various kinds of cardiac disease. J Moll Cell Cardiol 22: $1425-1438,1990$

28. Vannier C, Veksler V, Mekhfi H, Mateo P and Ventura-Clapier R: Functional tissue and development specifities of myofibrils and mitochondria in cardiac muscle. Can J Physiol Pharmacol 74: 23-31, 1996.

29. Perreault CL, Bin OH, Brooks WW, Ransil BJ and Morgan JP. Differential effects of cardiac hypertrophy and failure on right versus left ventricular calcium activation. Circ Res 67: 707-712, 1990.

30. Naito H, Arisawa J, Harada K, Yamagami H, Kozuka T and Tamura S: Assessment of right ventricular regional contraction and comparison with the left ventricle in normal humans: A cine magnetic resonance study with presaturation myocardial tagging. Br Heart J 74: 186-191, 1995.

31. Haddad F, Doyle R, Murphy DJ and Hunt SA: Right ventricular function in cardiovascular disease, part II: Pathophysiology, clinical importance, and management of right ventricular failure. Circulation 117: 1717-1731, 2008. 